stations across the Tibetan plateau and surrounding mountain ranges, at altitudes up to 6,000 metres, which will gather accurate snow measurements across the region that could augment SPICE's results.

In the longer term, however, "there will never be enough ground measurements to cover an entire mountain", says Michael Lehning, a climate scientist at the Swiss Federal Institute for Snow and Avalanche Research in Davos-Dorf, who is involved in the project. Results from SPICE will be used to calibrate airborne and satellite-based sensors, which use techniques such as microwave, radar and laser ranging to survey much larger areas.

"The idea is to push remote sensing to be accurate enough for use in mountains," says Lehning. "It's still a long way off, but SPICE is a good starting point." -

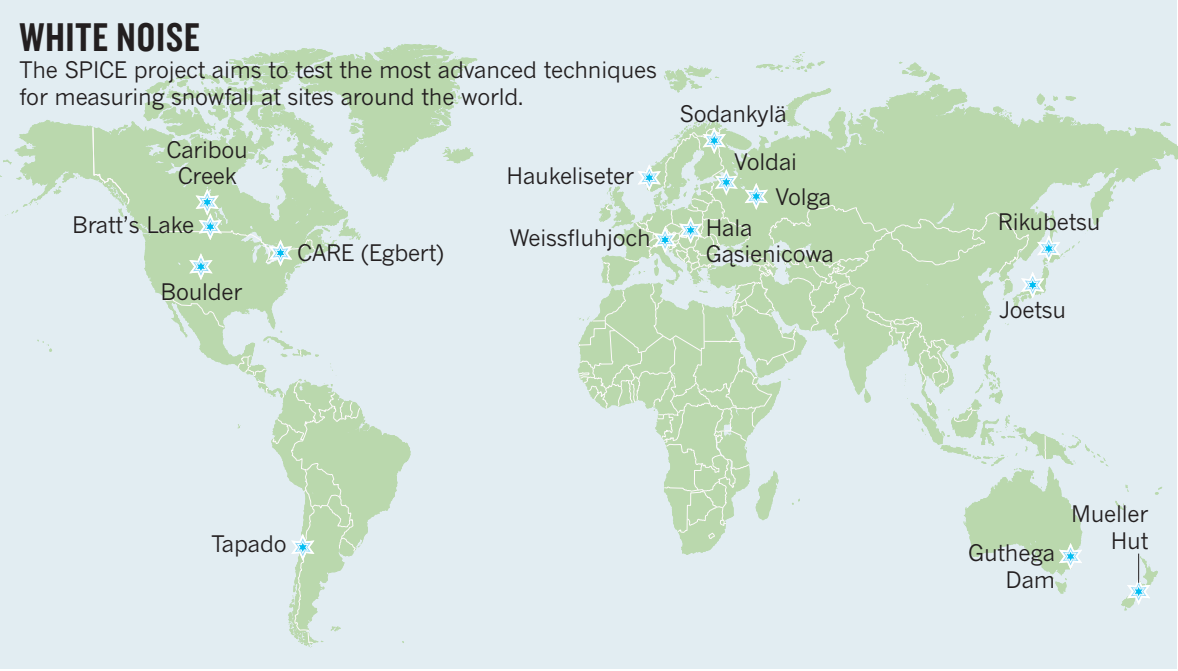

\title{
ALTERNATIVE MEDICINE
}

\section{Chelation-therapy heart trial draws fire}

\section{Critics not persuaded that metal-snaring treatment works.}

\section{BY EWEN CALLAWAY}

$\mathrm{W}$ ith millions of Americans regularly using complementary medicines, researchers usually applaud efforts to test and debunk folk treatments such as echinacea, a herbal supplement often deployed against the common cold. But what if a trial shows that an alternative therapy might work?

That is the case for a study funded by the US National Center for Complementary and Alternative Medicine (NCCAM), part of the National Institutes of Health (NIH) in Bethesda, Maryland. The trial hints that a fringe therapy intended to sop up metal ions in the blood might reduce participants' risk of heart attack. Critics are attacking both the rigour of the study and the records of some of its investigators, complicating the NCCAM's efforts to answer charges from some researchers that it funds quackery, and raising questions about whether the centre's US $\$ 128$ million annual budget is being spent wisely.

The Trial to Assess Chelation Therapy (TACT) was a 10-year, \$31.6-million study involving 1,708 participants at 134 centres. It aimed to test whether weekly infusions of a salt of ethylenediaminetetraacetic acid (EDTA) can lower the risk of repeat heart attacks. EDTA is a chelating agent: the molecule is peppered with electron-rich nitrogen and oxygen atoms, which can grab and hold onto positive metal ions (see picture). The US Food and Drug
Administration has approved one salt, calcium disodium EDTA, to treat lead poisoning.

Proponents of chelation therapy for heart disease initially speculated that EDTA could also cleanse the blood of calcium ions, a component of the atherosclerotic plaques that block blood vessels. But evidence against that hypothesis led them to suggest alternative mechanisms, for example that the molecule captures other metals, preventing heart-damaging inflammation. In spite of the uncertainty, the treatment is already big business: a 2007 US government survey estimated that, every year, 110,000 Americans undergo chelation therapy,

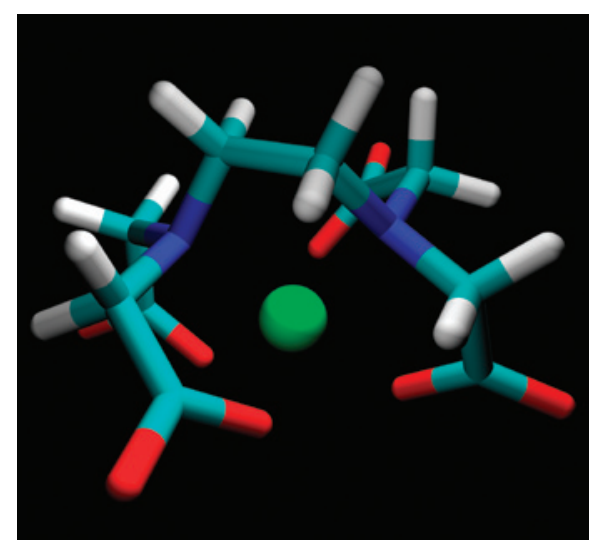

The electron-rich oxygen (red) and nitrogen (dark blue) atoms in ethylenediaminetetraacetic acid can grab and hold onto positive metal ions (green). which can cost thousands of dollars per course. According to TACT, which the NCCAM cofunded along with the National Heart, Lung, and Blood Institute (NHLBI), the therapy shows signs of working. On 4 November at the annual meeting of the American Heart Association in Los Angeles, California, trial leaders reported that $26 \%$ of patients who received infusions of disodium EDTA went on to suffer a heart attack, stroke or other heart problem, compared with $30 \%$ of patients on a placebo a statistically significant difference.

Many medical researchers were quick to question the results. Perplexingly, the benefit was observed only among participants with diabetes, and $30 \%$ of participants dropped out of the trial, undermining comparison between the treatment and placebo. Critics also note that nearly two dozen trial co-investigators have been disciplined by state medical boards for infractions ranging from insurance fraud to providing ineffective treatments. "They offer aromatherapy, crystal therapy and every imaginable wacky form of medicine. You can't do high-quality research at sites like that," says Steven Nissen, a cardiologist at the Cleveland Clinic in Ohio. "We wasted \$30 million and 10 years on an unreliable study."

He worries that the research will be used to support unapproved chelation therapies, which have been linked to heart attacks and death. "Public harm is going to come out of this. People are going to get bilked out of a lot of money. People are going to die."

Kimball Atwood, an anaesthesiologist at Tufts University School of Medicine in Boston, Massachusetts, and one of TACT's most vociferous critics, argues that the trial has been troubled from the beginning. In a paper titled 'Why the NIH Trial to Assess Chelation Therapy (TACT) should be abandoned' (K. C. Atwood et al. Medscape J. Med. 10, 115; 2008), he claimed that trial proponents had mischaracterized earlier studies of chelation therapy 
- by suggesting that their results were equivocal and necessitated a larger followup. Atwood says that the earlier studies in fact found that the treatment was ineffective at preventing heart attacks.

In 2008, TACT was suspended after regulators learned that subjects were not being given calcium disodium EDTA, as implied on informed-consent forms - instead, they were being infused with the slightly different salt disodium EDTA, for which the FDA had revoked approval. The trial resumed after consent forms were reworded to include warnings, such as "death is a rare complication of EDTA infusions".

Josephine Briggs, director of the NCCAM, declined to comment on TACT until the results are published in a journal. The principal investigator, cardiologist Gervasio Lamas of Mount Sinai Medical Center in Miami Beach, Florida, says that the study's findings were a surprise and deserve following up. He adds that the trial consent forms were approved by the NIH and multiple institutional review boards. Gary Gibbons, director of the NHLBI, says that his institute stands by the study's methodology.

But critics charge that TACT is simply the latest example of dubious research into unproven therapies supported by the NCCAM. Some argue that even highquality studies would have little value, because negative results are unlikely to sway ardent practitioners. "Show me one alternative medication or procedure that was studied, found to not work, and was abandoned by practitioners. I'm not aware of any," says Steven Novella, a neurologist at Yale University in New Haven, Connecticut. Briggs, who previously led the NIH's kidney-disease research, points out that echinacea sales fell after an NCCAMfunded study showed it was ineffective against colds (R. B. Turner et al. N. Engl. J. Med. 353, 341-348; 2005). With the centre's research showing that Americans spend about $\$ 34$ billion on alternative medicine each year, "we think it's really important to bring some science into this", she says.

Briggs adds that the NCCAM's critics often misrepresent the centre's research, focusing on studies of herbal supplements such as lavender oil but ignoring multimillion-dollar grants for more-mainstream science. Among the largest studies funded by the centre this year are a computational analysis of the human microbiome and an effort to use brain imaging to understand and treat chronic back pain.

Novella and other NCCAM critics do praise Briggs for bringing increased accountability to the centre, and for boosting the rigour of the research it funds. But "even if you did pristine research under the NCCAM", says Novella, "it's what you're studying that is the problem".

BIOTECHNOLOGY

Pig geneticists go
the whole hog

\section{Genome will benefit farmers and medical researchers.}

BY ALISON ABBOTT

$\mathrm{T}$ 1. J. Tabasco is something of a porcine goddess at the University of Illinois, Urbana-Champaign, where her ruddy, taxidermied head looks down from the office wall of geneticist Lawrence Schook. Now she has been immortalized in this week's Nature ${ }^{1}$ not by name, but by the letters of her DNA.

Scientists are salivating. For the past couple of decades they have been slowly teasing information from the pig genome, applying it to breed healthier and meatier pigs, and to try to create more faithful models of human disease. This week's draft sequence of T. J's genome (see page 393), with its detailed annotation - a 'reference genome' - will speed progress on both fronts, and perhaps even allow pigs to be engineered to provide organs for transplant into human patients. "Agriculture in particular will benefit fast," says Alan Archibald of the Roslin Institute in Edinburgh, UK, one of the paper's lead authors. "The pig industry has an excellent track record for rapid adoption of new technologies and knowledge."

T. J., a domestic Duroc pig (Sus scrofa domesticus), was born in Illinois in 2001. The next year, Schook and his colleagues generated a fibroblast cell line from a small piece of skin from her ear and commissioned clones to be created from it, so that they could work on animals all with the same genome. One set of clones was created at the National Swine Resource and Research Center (NSRRC) in Columbia, Missouri, along with genetically engineered pigs with genes added or deleted to mimic human diseases. "Making such pigs has got increasingly easier as knowledge of the genome increases," says physiologist Randall Prather, a co-director of the NSRRC, which is funded by the National Institutes of Health (NIH).

The NIH launched the NSRRC in 2003 to encourage research in pig disease models. Pigs are more expensive to keep than rodents, and they reproduce more slowly. But the similarities between pig and human anatomy and physiology can trump the drawbacks. For example, their eyes are a similar size, with photoreceptors similarly distributed in the retina. So the pig became the first model for retinitis pigmentosa, a cause of blindness. And four years ago, researchers created a pig model of cystic fibrosis ${ }^{2}$ that, unlike mouse models, developed

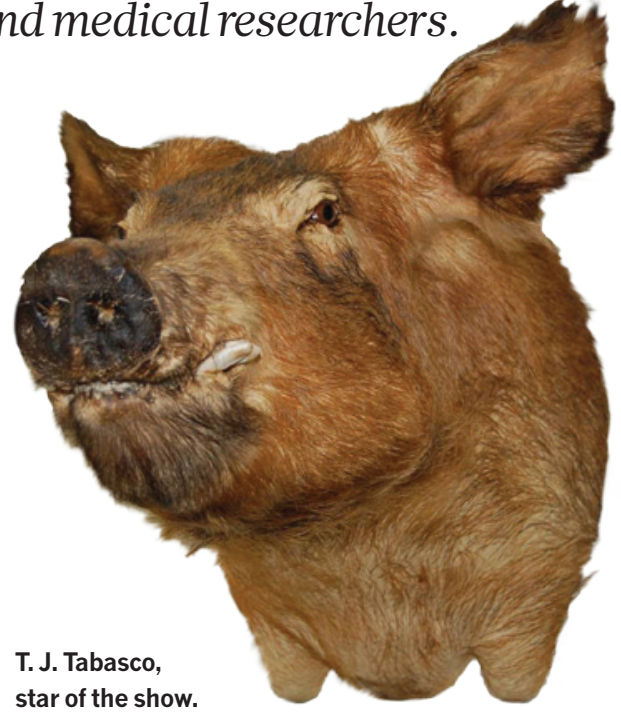

symptoms resembling those in humans.

Geneticist and veterinarian Eckhard Wolf at the Ludwig-Maximilian University in Munich, Germany, has exploited the similarity between the human and pig gastrointestinal system and metabolism - like us, pigs will eat almost anything and then suffer for it - to develop models of diabetes. One pig model carries a mutant transgene that limits the effectiveness of incretin, a hormone required for normal insulin secretion ${ }^{3}$. Mice with the transgene developed unexpectedly severe diabetes, but the pigs have a more subtle pre-diabetic condition that better models the human disease. "This shows the importance of using an animal with a relevant physiology," says Wolf.

Pig models are now being developed for other common conditions, including Alzheimer's disease, cancer and muscular dystrophy. This work will be enriched by the discovery, reported in the genome paper, of 112 gene variants that might be involved in human diseases. Knowledge of the genome is also allowing scientists to try to engineer pigs that could be the source of organs, including heart and liver, for human patients. Pig organs are roughly the right size, and researchers hope to create transgenic pigs carrying genes that deceive the immune system of recipients into not rejecting the transplants.

Back on the farm, early knowledge about the pig genome led to the discovery in 1991 of a gene involved in porcine stress syndrome, in which the stress of overheating, being moved or even having sex causes the animals to die suddenly ${ }^{4}$. It then became possible to test for the 